\title{
BEGRAFNISGEBRUIKE, DIE HIERNAMAALS EN DOODSBESOEDELING IN ANTIEKE GRIEKELAND
}

\author{
L Cilliers \& F P Retief (Universiteit van die Vrystaat)
}

\begin{abstract}
Funerary practices, the hereafter and pollution in ancient Greece
Funerary practices in ancient Greece were influenced by contemporary views on the hereafter and concepts of pollution, but also by an endeavour to limit costs and to prevent the burial procedure from causing inconvenience to the community or creating the opportunity of exploitation for ulterior political motives. Plato (Hippias Maior $291 \mathrm{~d}$ and e) said that it was the ideal of any Greek was to be rich, healthy and honoured, to reach a good old age, to bury his parents in a fitting way, and thereafter to be buried himself by his children with the necessary honours. In this study the views current in Greece, and Attica in particular, from the eight to the fourth centuries $\mathrm{BC}$ on the handling of the dead are investigated. The sources consulted were Homer's epic poems, archaeological data and vase paintings, as well as the writings of later historians, philosophers and other prominent persons.
\end{abstract}

\section{Siening oor hiernamaals}

Daar was nooit volledige Pan-Helleense eenstemmigheid oor die hiernamaals en meer bepaald oor Hades nie, maar daar was tog redelik aanvaarde hoofstroomdenke en -teorieë wat 'n duidelike ontwikkelingsgang vanaf Homeros se tyd tot die klassieke era getoon het (Garland 1985:1-12). Alhoewel daar veral in die klassieke era onder filosowe uiteenlopende sienings oor die onsterflikheid van die siel en aanverwante sake was (Kurtz \& Boardman 1971:330-333), word die heersende siening oor die bestaan van 'n hiernamaals vervolgens uiteengesit.

Tydens die doodsoomblik verlaat die siel (psuche) die liggaam deur die mond, of 'n oop oorlogswond, indien van toepassing. Volgens Homeros ontsnap ook ander elemente uit die liggaam, naamlik die thumos (vanuit die hart) en die vitale gees (aion) vanuit jongmense. Hulle speel egter geen verdere rol nie. Die lyk wat agterbly, verrot en is van geen verdere belang nie (Sourvinou-Inwood 1995:61-63, 323-320).

\section{Hades}

2.1 Uit die Odusseia wat uit die laat agste eeu vC dateer, word verneem dat Hades 'n donker plek onder die aarde is (Od.11.18-19). Die siening was dat alle mense sterf, alhoewel dit blyk dat koning Menelaos wat direk na Elisium gegaan het sonder om te sterf, wel 'n enkele uitsondering was (Hom. Od. 3. 236-8; 4. 561-5).

Daar was vele roetes na Hades, deur gange in die aarde of deur ver wes te beweeg en oor die rand van Okeanos (die Wes-see) wat die wêreld omring, te vaar. Hades was ook omring deur water wat soms as 'n see (Okeanos) of riviere voorgestel word waarvan die Stuuks die bekendste was, maar wat ook die Acheron, Kokutos en Puriphlegethon ingesluit het (Hom. Od. 10. 501-2; Sourvinou-Inwood 1995:56-63). Die siel wat by Hades aanland, word egter deur siele binne Hades verhoed om die water oor te steek voordat die liggaam begrawe is, en moet dan in 'n neutrale gebied duskant die water wag. Hades is deur ' $n$ poort binnegegaan waar die veelkoppige monsterhond Kerberos 
waggehou het, en enige wesens wat Hades weer probeer verlaat, verslind het (Hes. Theog. 767-75; Sourvinou-Inwood 1995:106-7, 309).

Binne Hades het die siele 'n neutrale, ongedifferensieerde skadubestaan gevoer, sonder eie karakterkenmerke en sonder insig. Daar was geen straf of beloning vir aardse handelinge nie, en geen kontak met die lewendes nie (Hom. Od. 11. 476; Garland 1985:1-2).

Sourvinou-Inwood (1995:66-70) wys egter daarop dat die Homeriese eposse sekere weersprekings oor die aard van die Onderwêreld bevat. Sy stel voor dat Homeros aanvanklik die oorspronklike verhale uit die pre-Homeriese era saamgevat het, maar dat sekere aanpassings selfs in sy tyd na vore gekom het, dat vroeë en laat komponente van die gedigte dus nie noodwendig opvattinge van dieselfde era weerspieël nie, en dat Odusseia Boek 24 byvoorbeeld eers later, gedurende die archaïese era, geskryf is (Sourvinou-Inwood 1995:94-103). So is daar in die Homeriese gedigte (Od. 24 uitgesluit) voorbeelde van siele in Hades wat mekaar wel herken het (Od. 11. 542-67), van hierargieë wat ontstaan het (Od. XI. 489-91), van die straf van oortreders (Il. 3. 276-80; 19. 359-60; Od. 11 passim), en selfs van Odusseus wat Hades besoek en met sy ou vriende kontak maak (Od. 11. 485-6). Die siele word ook bewus van vriendelike of vyandige rituele wat by hul grafte uitgevoer word (Garland 1985:4). Die stelling word voorts gemaak dat die konsep van Elisium (die Paradys) nie Minoïes in oorsprong was nie, maar aan Homeros toegeskryf moet word (Sourvinou-Inwood 1995:32-56).

2.2 Tydens die archaïese era (die agste tot die sesde eeu $\mathrm{vC}$ ) verander die konsep van die hiernamaals. Twee begeleidende figure (psuchopompoi) tree nou na vore wat die siel na Hades vergesel:

2.2.1 Volgens Odusseia 24.98-100 ontvang Hermes (Kullenios, Chthonios), boodskapper van die gode, nou die siel van die gestorwene van Thanatos, die doodsagent, en met sy kêrukeion (staf) begelei hy die siel langs 'n vasgestelde roete na die Onderwêreld. Hier mag die siel Hades nou selfs voor begrawing van sy liggaam binnetree, maar eers na die begrafnis word hy ten volle geïntegreer. Hermes is die enigste god wat na die Onderwêreld mag afdaal (SourvinouInwood 1995:103-106).

2.2.2 Chronologies later as Hermes, verskyn die bootsman, Charon, op die toneel. Hy word nie in Odusseia 11 of 24 genoem nie, en ontstaan waarskynlik uit die (verlore) epiese Minuas-verhaal uit die laat sewende eeu vC. Met sy boot vervoer Charon die siele wat deur Hermes aan hom gelewer word, oor die strook water (die rivier Acheron, of die meer Acherousia) na Hades, waar Kerberos steeds die ingangspoort bewaak (Sourvinou-Inwood 1995:303-320).

Binne Hades is die siele nie meer ongedifferensieerde, insiglose wesens nie; hulle dra kennis van wat met die lewendes aangaan. Daar is ook nou straf vir vorige oortredings (bv. die aflegging van vals ede) en helde word vereer. Hulle kan met mekaar kommunikeer alhoewel dit oënskynlik gepaard moet gaan met die drink van offerbloed (Hom. Il. 24. 591-5; Od. 11.35-43). Garland (1985:10) stel dit dat Hades mettertyd 'n aangenamer plek word, en dat die afstand tussen dooies en lewendes afneem. Nie alle mense sterf meer nie deurdat sommige direk na Elisium geneem word sonder om deur Hades te gaan (SourvinouInwood 1995:106-107). 
2.3 In die klassieke era (vyfde en vierde eeue vC) is die rol van die psuchopompoi uitgebrei. Hermes begelei nou nie slegs siele na Hades nie, maar fasiliteer soms hul tydelike terugkeer na die lewendes. Hy tree ook op as kêruks (middelman) om siele te sensitiseer vir boodskappe vanaf die lewendes (Sourvinou-Inwood 1995:304-5). Nekromansie begin floreer (Garland 1985:3). Die gebruik van vervloekingstablette (katadesmoi) wat in grafte geplaas is en waardeur dooies moet help om vloeke uit die Onderwêreld oor lewendes te bring, kom in gebruik (Garland 1985:6). Vanaf $500 \mathrm{vC}$ verskyn Charon se afbeelding gereeld op vase by grafte (Sourvinou-Inwood 1995:321324). Die gebruik dat dooies 'n obol-muntstuk aan Charon betaal wat in die gestorwene se mond geplaas is, is 'n relatiewe laat ontwikkeling; die vroegste literêre verwysing hierna kom voor in Aristophanes se Paddas (reel 140) (Garland 1985:23).

Die Eleusiniese/paradys-konsep ontwikkel sterk in die vyfde en veral vierde eeue $\mathrm{vC}$, en gaan gepaard met religieuse groepvorming (Garland 1985:18; SourvinouInwood 1995:424-425). Aanvanklik het uitverkorenes wat nie sterf nie direk na Elisium verhuis, maar veel later ontstaan die siening dat 'n tribunaal van 3 "regters" (Rhadamanthos, Minos en Aiakos) in Hades 'n oordeel vel oor alle siele, en die regverdiges na Elisium verwys maar die res vir straf na dié deel van Hades bekend as Tartaros stuur (Morford \& Lenardon 1995:295).

\section{Doodsbesoedeling}

Die konsep dat dood (en geboorte) gepaard gaan met die kultureel-religieuse besoedeling van diegene daarby betrokke is algemeen in die Antieke aanvaar, alhoewel die presiese omvang daarvan van streek tot streek en selfs van tyd tot tyd gewissel het. Hierdie besoedeling is nie primêr op higiëniese oorwegings gebaseer nie, maar was vir die gode aanstootlik, dus is geboorte en sterfte nie in heilige plekke soos tempels of op die eiland Delos toegelaat nie. Dit was nie altyd duidelik presies hoe besoedeling individue benadeel het nie, maar kontak met die gode is wel daardeur verbreek totdat die gepaste reiniging afgehandel is. Besoedeling het onder andere vir die tyd van rou gegeld. (Die komplekse oorsprong van die besoedelingskonsep word later bespreek.) Die hantering van besoedeling is gedeeltelik per wet geregistreer (Parker 1985:32-34).

Die huis of ekwivalente ruimte waarbinne die dood ingetree het, is as besoedel beskou. Indien 'n persoon op straat gesterf het, moes die stadswyk gereinig word. Water in die huis was outomaties besoedel, en in sekere streke ook die vuurherd (Dem. Mac. 43.51-8; Parker 1983:35-8).

Alle persone wat aan die lyk raak of die doodshuis binnekom, was besoedel - so ook diegene wat besoedeldes aangeraak het. Sekere nabye familielede (soos deur die wet bepaal) was outomaties besoedel (Parker 1983:38-40). In Sparta is in een stadium vereis dat by ' $n$ koning se dood elke huishouding 'n man en 'n vrou moes aanwys wat dan besoedel sou wees (Her. Hist. 6.58.1). Gestorwe vreemdelinge, slawe en kinders was minder besoedelend en 'n doodgebore baba kon slegs iemand besoedel iindien dit volledig ontwikkel was (Parker 1983:41-2; Marshall 2000:9, 10, 15). Helde, stigters van gemeenskappe en soldate wat op die slagveld gesterf het, het min of gladnie besoedel nie, en verbasend genoeg was dit ook die geval met tereggestelde kriminele (Marshall 2000:12, 13; Parker 1983:42, 46).

Grafte het min besoedeling meegebring (behalwe dié van helde), maar die beendere en relieke van dooies het weer besoedel. Feeste vir die gestorwenes, soos die Anthesteria (waar 
dooies tradisioneel teenwoordig was), kon mense lig besoedel (Marshall 2000:12; Parker 1983:38-9).

\section{Begrafniswetgewing}

Die mitologiese eerste koning van Athene, Kekrops, het tradisioneel die oorspronklike begrafnisrituele ingestel (Cic. Leg. II. 25-63). Ploetarchos (Lyc. 27) beweer dat die legendariese Lukoergos, koning van Sparta, in ongeveer die agste eeu vC probeer het om die doodsproses te ontmitologiseer deur goedkeuring te verleen aan begrafnisse binne stede asook prominente grafstrukture in die nabyheid van heilige plekke. Lyke moes slegs in 'n rooi kleed gewikkel, begrawe word, bedek met olyfblare (sonder grafoffers), en name op grafstene was verbode (behalwe by soldate); die routyd is beperk tot elf dae, waarna 'n offerande aan Demeter gebring moes word. Vroue is versoek om luid en lank by grafte te weeklaag.

Latere wetgewing het, in teenstelling hiermee, wel doodsbesoedeling in ag geneem. Wetgewers het in die reël gepoog om die begrafnisprosedure plegtig maar sonder ongerief vir die algemene publiek te reël. Die misbruik van 'n begrafnis om aandag te trek (veral met politieke oogmerke) is verbied, sowel as oordadige swier en uitgawes (Garland 1989:1-3).

4.1 Solon (in die vroeë sesde eeu vC) het volgens Demosthenes (Mac. 43.62), Cicero (Leg. II 25.63) en Ploetarchos (Solon 21) uitvoerige wette uitgevaardig wat lank die norm gebly het en, volgens Cicero, later feitlik onveranderd in die Romeinse Twaalftafelwette opgeneem is. In hoofsaak was dit reëls vir die binneshuise lyksvoorbereiding (prothesis), die lykstoet (ekphora, voor dagbreek), begrafnis- en verassingseremonies, grafoffers en rou-betuiging, asook opvolgbesoeke aan die graf uitgevaardig. Hy het nie spesifieke beperkings op grafversierings geplaas of doodsbesoedeling in detail vermeld nie, waarskynlik omdat veral die hantering van laasgenoemde reeds stewig gevestig was. Latere redenaars (Demosthenes Mac. 43.578) het beweer dat hy ook maatreëls ten opsigte van lyke op straat en die hantering van selfmoordsterftes afgekondig het. Dit is moontlik dat Solon die Genesia (die jaarlikse herdenking van gestorwenes op 'n spesifieke datum) ingestel het ten einde die wanorde wat deur grafherdenkings op oorledenes se verjaarsdae ontstaan het, hok te slaan (Garland 1989:4). Ploetarchos (Solon 12.8) beweer ook dat Epimenides in hierdie tyd sterk opgetree het om oordadige geweeklaag deur vroue te beperk omdat dit deur opponerende families en politici vir eie gewin uitgebuit is (Garland 1989:3-5).

4.2 Volgens Cicero (Leg. II. 64) is Solon se wette later in die sesde eeu vC deur wetgewing aangevul wat onder andere die grootte van grafte en grafversierings beduidend beperk het. Hierdie post aliquando wette van ongeveer 530 vC (Kurtz \& Boardman 1971:121141 ) is waarskynlik deur Peisistratos (en later Kleisthenes) ingestel, en het onder andere bepaal dat die grafversiering nie groter mag wees as 'n struktuur wat binne drie dae deur tien werkers opgerig kan word nie. Ongeveer hierdie tyd het geverfde terracottaplakette van grafte verdwyn; na $500 \mathrm{vC}$ is dit gevolg deur archaïese grafsuile (stelai) (Garland 1989:5-7).

Charondes van Katana het in die laat sesde eeu vC oormatige roubetoon by grafte verbied, en aanbeveel dat dit vervang word deur die blymoedige bring van vrugte-offers (Garland 1989:8). In Delphi het die Labuade-familiegroep (vyfde eeu vC) in 'n beleidsverklaring uitspattige begrafnisrituele verbied, en gelas dat die lykstoet stil en 
sonder onderbreking na die graf moes beweeg, dat daar nie by ander grafte as dié van die gestorwene geweeklaag mag word nie, en dat jaarlikse doodsherdenkings beperk moes word (Garland 1989:8-9). Ongeveer dieselfde tyd is Solon se wette by Iulis op Keos herbevestig, die misbruik van doodsreëlings vir politieke of familiedoeleindes verbied, reinigingsrituele opgeskerp en die triakosta (dertigstedag-feesviering) afgeskaf (Garland 1989:11-13).

4.3 Teen $430 \mathrm{vC}$ het Attiese grafsuile hul verskyning gemaak; met verloop van tyd gevolg deur groter en luukser grafte en begrafnisrituele. In die laat vierde eeu vC volg Demetrios van Phaleron se wetgewing wat nie slegs beperkings plaas op uitspattige begrafnisse en groot grafstrukture nie, maar ook spesiale amptenare met boetebevoegdheid daarstel. Dit het feitlik onmiddellik 'n positiewe uitwerking gehad (Cic. Leg. 2.60; Garland 1989:8).

4.4 Plato ( $L e g .958 \mathrm{~d}-960 \mathrm{c}$ ) verwys in die vierde eeu vC na begrafniswetgewing wat onder andere bepaal dat onsekerheid oor heilige rites na 'n aangewese amptenaar verwys moet word vir 'n finale oordeel; dat daar geen grafte op landbougrond mag wees nie; dat grafversierings nie groter mag wees as wat binne vyf dae deur vyf werkers opgerig kan word nie, en dat grafstene slegs vier "heroïese inskripsiereëls" mag bevat; dat die geordende ekphora teen dagbreek buite die stadsmure moes wees, en dat spesiale maatreëls vir die begrafnis van selfmoordgevalle, moordenaars en ander geweldenaars, asook staatsbegrafnisse, sal geld.

\section{Begrafnisprosedure in die klassieke era}

In teenstelling met ander state in Griekeland was dit in Attika die gebruik dat sy burgers tuis begrawe word. 'n Verbod op die teraardebestelling van 'n burger van Attika in sy tuiste was inderdaad 'n ernstige straf (Kurtz \& Boardman 1971:142). Garland (1985:28) wys egter daarop dat die literatuur waarskynlik vanweë bovermelde algemene wetgewing min beskrywings van spesifieke begrafnisse bevat. Argeologiese bevindings en die bestudering van relevante vaastekeninge (wat tipies by grafte gelaat is) vertel meer. Daar was algemene aanvaarding dat lyke behoorlik begrawe moes word - selfs dié van jou vyand. Ignorering hiervan kon jou blootstel aan goddelike strawwe, alhoewel vrees hiervoor teen die klassieke era heelwat afgeneem het (Parker 1983:43-45). Die tipiese begrafnisprosedure kan soos volg saamgevat word:

\subsection{Voorbereiding van die lyk (prothesis)}

Volgens wet moes die prothesis binneshuis geskied - gewoonlik in die sterftehuis. Die lyk is gewas, gesalf, geklee (tipies in wit of rooi material) (Parker 1983:3-5) en versier met 'n kroon, linte en blomme; juwele is selde gebruik. Hierdie taak is gewoonlik deur vroue (nabye familielede) oor die ouderdom van sestig jaar vervul. Vorms van balseming was bekend maar is selde gebruik (Garland 1985:34). Die lyk is dan op 'n plankbed (klinê), bedek met 'n kleed (stroma), geplaas, die kop op 'n kussing, en so geposisioneer dat die voete na die deur gewys het.

Volgens Plato (Leg. 959) is die lyk lank genoeg (gewoonlik een dag) in hierdie posisie gelaat om seker te maak dat hy/sy wel dood is, en om geleentheid te gee vir tradisionele roubetoon. Volgens vaastekeninge het mans die lyk benader met die regterhand gelig, terwyl vroue teen hul kop en bors geslaan het. Vroue se geweeklaag is 
soms aangevul deur betaalde musici (fluit-, harp- en lierspelers - gewoonlik meisies) wat teen 'n vasgestelde tarief opgetree het (Arist. Ath. Pol. 50). Professionele roubeklaers (veral Kariese vroue) is ontmoedig.

Ten einde die besoedelde roubeklaers geleentheid te gee om by hul vertrek te was, is 'n groot fles met skoon water van elders by die deur geplaas (die huis se water is as besoedeld beskou). Dit het ook as waarskuwing vir verbygangers gedien dat daar 'n sterfte in die huis was. Spesiale boomtakke of blare is oënskynlik nie vir dié oogmerk aangebring nie (Parker 1983:35).

\subsection{Lykstoet (ekphora)}

Die lyk is gewoonlik op die derde dag voor dagbreek na die graf buite die stadsmure gedra - aanvanklik deur familie of vriende (of deur 'n perde- of muilkar), maar later is betaalde lyksdraers gehuur. Die liggaam is volgens voorskrifte onder 'n kleed toegemaak, sodat slegs die kop oop was.

Die stoet moes hoofweë vermy en nie langs die pad stop nie. Mans wat die stoet begelei, het voorlangs gestap, gevolg deur die vroue, wat weereens nabye familielede en oor sestig jaar oud moes wees. Geen dergelike beperking is op mans geplaas nie. Daar moes geen geweeklaag of lyksange wees nie (behalwe by amptelike begrafnisse), maar volgens Solon kon tot tien musici (wat gewoonlik Kariese musiek gespeel het) die stoet vergesel. Uit vrees vir besoedeling was daar nooit priesters teenwoordig nie (Parker 1983:36).

\subsection{Begrawing}

Die begrawingsritueel van 'n lyk, of van die as (na verassing), was 'n eenvoudige prosedure, alhoewel min uitvoerige beskrywings daarvan vandag beskikbaar is. In vroeër eras is diereoffers en selfs menslike offers by die graf gebring. Homeros (Il. 18.336-7) beskryf byvoorbeeld die offerande van tien Trojaanse jeugdiges by die begrafnis van Patroklos, en krygshelde se vroue en perde is soms saam met hulle begrawe. Daar is getuienis dat dit in uitsonderlike gevalle ook in die klassieke era gebeur het, alhoewel Solon selfs die offer van 'n os by die graf verbied het (Garland 1985:34-36, 39; Kurtz \& Boardman 1971:144-146).

Die lyk is soms in 'n kis, maar meer dikwels in 'n kleed toegedraai, begrawe. $\mathrm{Na}$ verassing is die as in 'n houer ook in 'n graf begrawe. Bo-oor die toegegooide graf is tradisioneel graan gestrooi, volgens Cicero ( $L e g .2 .25,63)$. Dit word algemeen aanvaar dat dit deel van die ta trita-seremonie kon gewees het (wat weer drie dae later herhaal is), gevolg deur die drink van 'n offerdrank (choê) en die giet van plengoffers (spondai) vir die gode. Verdere geskenkoffers vir die gestorwene is op of in die graf gelaat.

Die familie is hierna dadelik terug na die doodshuis vir 'n feesmaal (perideipnon) waar hulle, versier met krone en sierkranse, gesellig verkeer het en die gestorwene se lewe herdenk en sy dade aangeprys het. Garland (1985:37) beweer dat dit aanvaar is dat die gees van die oorledene hier teenwoordig was.

Dis onseker of daar soms op die derde dag weer 'n seremonie by die graf was, maar op die negende dag het die ta enata-ritueel (waarvan ons geen detail ken nie) wel daar plaasgevind, en op die dertigste dag die triakosta-seremonie. In Athene het die rouperiode nou tot 'n einde gekom, maar dit het verskil van plek tot plek (Kurtz \& Boardman 1971:149, 150). In dele van Griekeland (byvoorbeeld die dorpie Iulis op 
Keos waar daar ' $n$ inskripsie gevind is met uitvoerige begrafnisregulasies) is die triakosta-seremonie in die vyfde eeu afgeskaf (Garland 1985:40).

\subsection{Spesiale gevalle}

Volgens Plato (Leg. 909 b en c; Garland 1989:4) is tereggestelde kriminele nie begrawe nie, maar in die see, in gruisgroewe of in putte gegooi. Persone wat selfmoord gepleeg het, se regterhand is afgekap voor hulle begrawe is; indien die persoon opgehang is, is die tou en boomtak (of ander struktuur waaraan die tou vasgemaak was) vernietig (Parker 1983:41, 42; Garland 1989:4). Slawe was geregtig op 'n volledige begrafnis en is dikwels soos 'n lid van die familie begrawe. Die grafte was eenvoudig en geen offergeskenke is gelaat nie omdat dit 'n populêre opvatting was dat slawe geen hiernamaals beleef nie. Daar was geen afsonderlike begraafplase vir slawe nie. Dié wat as soldate gesterf het, is normaalweg soos hul krygsmakkers vereer en begrawe. Na Marathon en Plataia is slawe-soldate egter wel in aparte grafte begrawe (Kurtz en Boardman 1971:198-99).

Onbekende dooies wat op paaie of strate gevind is, is deur die stadskontroleur met die hulp van slawe begrawe (Arist. Ath. Pol. 50.2).

\subsection{Reiniging en ander opvolgrites}

Op die derde dag na die begrafnis is die doodshuis en besoedelde persone gereinig, lg. deur te was met onbesoedelde water (d.w.s. nie vanuit die huis nie). Die huis is waar moontlik met seewater of met ander onbesoedelde water besprinkel, en met grond bestrooi. Die prosedure moes deur 'n vry persoon uitgevoer word. In Argos moes "nuwe vuur" van elders gebring word voordat daar weer in die vuurherd geoffer kon word (Parker 1983:35; Marshall 2000:10). Jaarlikse opvolgrites om die dooies te herdenk is volgens Kurtz en Boardman (1971:149-151) as uiters belangrik beskou selfs belangriker as die ta trita- en ta enata-seremonies. Ongelukkig is inligting hieroor karig en die procedures het ook met die tyd verander. Minstens sewe verskillende rites is wel by die graf uitgevoer, soms op die oorledene se verjaarsdag, en soms op wetlik vasgestelde dae van die jaar, waaronder die Genesia, Nemesia, Nekusia, Epitaphia en ander. Dit het waarskynlik offerandes van onder andere blomme, kranse en linte behels wat met groot eerbied en respek op die grafte geplaas is.

\section{6. $\quad$ Grafte en begraafplase}

Volgens Kurtz en Boardman (1971:49-58) is dooies in die negende en agste eeue vC binne en buite Griekse stede begrawe, en word navorsing bemoeilik deur onsekerheid oor presies waar stadsmure geleë was. Hierna word grafte algemeen buite stadsmure gevind, en in die sesde eeu vC was alle Atheense grafte buite die mure (Cic. Ad Fam. 4.12). In stede soos Sparta en Tarenton het begrafnisse egter selfs in die klassieke era nog binne stadsmure plaasgevind (Parker 1983:71).

In die Homeriese era het verassing meer dikwels voorgekom as teraardebestelling (Garland 1985:34). Grafte was eenvoudige vierhoekige put-strukture vir lyke of asbevattende urnes. Verassings is elders gedoen ('n sogenaamde sekondêre verassing). Grafkante was uitgevoer met gepakte klippe of klei. Lyke, gewoonlik in lyksklede eerder as houtkiste, is bedek met 'n klipblad of houtbalke. Die lyke van kinders is gewoonlik in groot kleipotte geplaas. ' $n$ Grondhopie is bo die toegegooide graf gestapel, en soms is 'n klein steenverhogie 
gebou. Indien 'n klip- of houtgrafmerker aangebring is, is dit met verassings sentraal bo-op die grafhopie geplaas en na begrawings by die koppenent. Groot klei-urnes is soms op die graf gelaat, en geskenkoffers vir die hiernamaals (kos, klere, juwele, wapens - selfs troeteldiere) is binne die graf of in spesiale holtes langs die graf geplaas (Kurtz \& Boardman 1971:49-58).

Die archaïese era (agste tot sesde eeu vC) is gekenmerk deur 'n selfs groter voorkeur vir verassing - behalwe by kinders wat direk begrawe is. Verassing word nou vir die eerste keer dikwels binne die grafholte gedoen. Klipbelyning van die grafput verdwyn, en terracottadoodskiste maak hul verskyning, terwyl geskenkoffers soos tevore hanteer word. Grafhope word al groter, en ornamentele grafstene en suile word populêr. Soos vermeld, neem hierdie gebruik na $530 \mathrm{vC}$ af, waarskynlik weens wetgewing (Kurtz \& Boardman 1971:68-74).

Tydens die klassieke era (vierde tot derde eeu vC) raak verassing en begrawing ewe populêr. Grafte word steeds in die literatuur onvoldoende beskryf. Grafstrukture raak eenvoudiger en meer eenvormig terwyl verassing sterk afneem en minder doeltreffend gedoen word. In die putgraf word lyke nou dikwels bedek met "tente" van skuinsgepakte teëls, eerder as klipblaaie of hout, en metaalhouers in plaas van keramiekurnes maak hul verskyning. Geskenkoffers sluit nou dikwels miniatuur-kleiarmpies in waarvan die betekenis duister is. Grafbedekkings raak groter en meer kompleks totdat die wette van Demetrios van Phaleron dit verbied. Groepgrafte (periboloi) raak populêr en prominente staatsgrafte vir Attiese soldate waar jaarlikse seremonies hulle afspeel, verskyn buite die Atheense mure (Thoek. II.6; Kurtz \& Boardman 1971:91-108).

\section{Gevolgtrekking}

Die konsep van die hiernamaals het in die vier eeue onder bespreking dus ingrypend verander. Veral opvallend is dat Hades verander het van 'n donker skaduwêreld waar siele van gestorwenes sonder intellek of identiteit neutraal voortbestaan het, totaal afgeslote van die lewendes, tot ' $n$ heelwat aangenamer plek waar siele 'n byna "aardse" bestaan kon voer, in kontak met mekaar kon kom en onder spesiale omstandighede selfs kontak kon maak met die lewendes. Nekromansie het hieruit gespruit — 'n praktyk wat volgens die Bybel (I Sam. 28:714) in die tiende eeu $\mathrm{vC}$ reeds deur die Kanaäniete beoefen is. Alhoewel waarskynlik reeds deur Homeros gekonseptualiseer, het die Elisium-gedagte van 'n paradys vir verdienstelike persone eers mettertyd ontwikkel. Aanvanklik het verdienstelikes dan ook nie gesterf nie, maar direk na Elisium gegaan. Eers veel later sou alle dooies eers na Hades gaan waar 'n beoordelingstribunaal die regverdiges na Elisium sou stuur en ander na Tartaros vir ewige straf.

Teen bovermelde agtergrond is die rol van geskenkoffers wat vir gestorwenes in die graf gelaat is, onseker (Kurtz \& Boardman 1971:206-209; 330-333). Oënskynlik is nooit geglo dat die siel op sy tog na Hades geskenke kon saamneem nie, en eers in die klassieke era sou Hermes die vermoë kry om kontak tussen siele van Hades en wesens op aarde te bewerkstellig. Volgens Lucianus is wel aanvaar dat plengoffers op grafte die siel in Hades versterk. By reïnkarnasie sou sulke geskenke teoreties vir die reis van die dooie van waarde kon wees, maar alhoewel enkele filosofiese groeperinge soos die Orfiste, Platoniste en Pithagoreërs 'n vorm van reïnkarnasie verkondig het, was dit nooit 'n algemene siening nie (Rose \& Parker 1979:1089). Lucianus (Oor begrafnisse 6-12) sou later met die konsep van 'n nadoodse bestaan die spot dryf en offers aan gestorwenes as belaglik afmaak. Die vraag kan 
gevra word of die meerderheid Grieke in die klassieke era inderdaad nog aan 'n hiernamaals geglo het, en of die rituele begrafnisseremonie, insluitend die offergawes in die grafte, nie 'n betoon van oorgelewerde sentimentaliteit en respek teenoor die gestorwene eerder as 'n religieuse oortuiging verteenwoordig het nie.

Oor die ontstaan en wese van die konsep doodsbesoedeling is reeds veel gespekuleer (Parker 1983:54-66; Garland 1985:45-47). Dit is duidelik dat die besoedelingskonsep van die klassieke era nog nie aan Homeros bekend was nie (Parker 1983:66-69). Krygers in sy epiese verhale word nie besoedel deur kontak met lyke nie, en die gode verafsku ook nie doodstonele nie (Hom. Il. 23. 52-53; 18. 23-25). Hesiodus suggereer dalk wel doodsbesoedeling deur geslagsomgang na 'n begrafnisseremonie af te raai (Hes. Op. 735-736) maar origens verwys besoedeling in die agste eeu $\mathrm{vC}$ na fisiese en nie metafisiese besoedeling nie. Ploetarchos (Lyc. 27.1) se stelling dat Lukoergos se wetgewing gepoog het om vrees en bygeloof uit die doodsproses te haal, mag dui op die bestaan van 'n besoedelingskonsep wat die Spartaanse koning dan spesifiek wou uitskakel. Tussen die agste en vyfde eeue $\mathrm{vC}$ het doodsbesoedeling as metafisiese, kultureel-religieuse konsep egter ferm wortel geskied, en alhoewel Solon se wette van die vroeg sesde eeu $\mathrm{vC}$ dit nie spesifiek noem nie, is dit in latere begrafniswetgewing opgeneem (soos aangetoon). Vrees vir higiëniese komplikasies wat met die dood geassosieer was, was feitlik sekerlik nie onderliggend aan hierdie besoedelingsdenke nie (Marshall 2000:8, 9, 16). Aanvaarding daarvan was vir deelnemers deel van die begrafnisprosedure, soos die dra van donker klere, en het nie 'n vrees-element meegebring nie (Parker 1983:35).

Garland (1985:45-47) meen dat die konsep waarskynlik 'n komplekse oorsprong gehad het. Teorieë dat dit gebaseer was op die bekamping van antieke demone, moontlik gekoppel aan die godin Hekate wat met die dood geassosieer was, word deur hom betwyfel. Moulinier (in Garland 1985:46) meen dat 'n diepliggende afkeer van die morbiede fisiese implikasies van die dood op metafisiese vlak as besoedelingskonsepte gemanifesteer is. Alhoewel Thoekudides in die vyfde eeu $\mathrm{vC}$ beskryf het dat epidemiese siektes van persoon tot persoon kon versprei (Retief \& Cilliers 1998:51), is die lyk in besoedelingsverband nie gesien as bron van siekte nie. Die feit dat 'n lyk in die klassieke era in sekere kringe as 'n religieus-heilige voorwerp beskou is, sou wel menslike kontak daarmee ontmoedig het omdat heiligheid vir die mens onvanpas en dus 'n "besoedeling" is (Garland 1985:146-7). Van Gennep postuleer dat die mens 'n neiging het om alle belangrike oorgangsperiodes in die lewe te ritualiseer, en dat die dood as finale onomkeerbare oorgangsproses na 'n toekoms wat met die gode geassosieer word, so geritualiseer is dat omstanders tydelik van die gode verwyder word ("besoedel word") (in Parker 1985:59-60). Parker (1985:64) meen ook dat die Grieke geglo het dat met die vertrek na die hiernamaals (die proses van sterwe) 'n tydelike heilige aura vanaf die gestorwene ook die naasbestaandes "besmet" het, en dat hulle van hierdie onvanpaste "besoedeling" bevry moes word voor die normale lewe kon voortgaan. Die vraag kan gevra word of die gemiddelde Griek in die klassieke era wel hierdie besoedelingskonsep fundamenteel begryp en aanvaar het, en of dit nie grotendeels 'n deur die wet bepaalde ritueel was wat sou verseker dat 'n paslike gaping tussen die mens en die verhewe goddelike magte tydens die doodsproses gehandhaaf word nie. 


\section{BIBLIOGRAFIE}

Bury, R G (trans1.) 1926. Plato. Laws. Loeb Classical Library. Vol. X and XI. Cambridge MA: Harvard University Press.

Fowler, H N (transl.) 1926. Plato. Greater Hippias et al. Loeb Classical Library. Vol. IV. Cambridge MA: Harvard University Press.

Garland, R 1985. The Greek way of death. New York: Cornell University Press.

Garland, R 1989. The well-ordered corpse: an investigation into the motives behind Greek funeral legislation. Bull. Inst. Class. Stud. 36.1-??

Godley, A D (transl.) 1922. Herodotus. Histories. Loeb Classical Library. Cambridge MA: Harvard University Press.

Grimal, P (ed) 1965. Larousse. World Mythology. New York: Prometheus Press.

Harmon, A M (trans1.) 1925. Lucian. On Funerals et al. Loeb Classical Library. Vol. IV. Cambridge MA: Harvard Univ. Press.

Keyes, C W (transl.) 1928. Cicero. On the Laws. Loeb Classical Library Vol. XVI. Cambridge MA: Harvard University Press.

Kurtz, D C, Boardman, J 1971. Greek burial customs. Thames \& Hudson: London.

Marshall, E 2000. Death and disease in Cyrene. In: Hope, V M, Marshall, E, Death and disease in the ancient city. London, New York: Routledge.

Morford M P O \& Lenardon, R J 1995. Classical Mythology ( ${ }^{\text {th }}$ Edition). New York: Longman.

Murray, A T (transl.) 1999. Homer. The Iliad. Loeb Classical Library. Vol. I \& II. Revised by W F Wyatt. Loeb Classical Library. Cambridge MA: Harvard University Press.

Murray, A T (transl.) 1995. Homer. The Odyssey. Loeb Classical Library. Vol. I \& II. Revised by G E Dimock. Cambridge MA: Harvard University Press.

Murray, A T (transl.) 1936. Demosthenes. Private Orations. Against Macartatus. Loeb Classical Library Vol. IV. Cambridge MA: Harvard University Press.

Parker, R 1983. Miasma: pollution and purification in early Greek religion. Oxford: Clarendon Press.

Perrin, B (transl.) 1914. Plutarch. Lycurgus, Solon et al. Loeb Classical Library. Vol. I. Cambridge MA: Harvard University Press.

Rackham, H (transl.) 1935. Aristotle. Athenian Constitution. Loeb Classical Library Vol. XX. Cambridge MA: Harvard University Press.

Retief, F P \& Cilliers, L 1998. The epidemic of Athens 430-426 BC. S.A. Medical Journal 88(1): 50-53.

Rowe, C R 1996. Transmigration. In: Oxford Classical Dictionary. Ed. Hornblower, S, Spawforth, A ( $3^{\text {rd }}$ Edition). Oxford. Clarendon Press.

Shackleton Bailey, D R (transl.) 2001. Cicero. Letters to his Friends. Loeb Classical Library Vol. XXV. Cambridge MA: Harvard University Press.

Smith, C F (transl.) 1928. Thucydides. History of the Peloponnesian War. Loeb Classical Library. Vol. I. Cambridge MA: Harvard University Press.

Sourvinou-Inwood, C 1995. "Reading” Greek death. Oxford: Clarendon Press.

Wender, D (transl.) 1973. Hesiod. Theogony. Works and Days. Theognis. Elegies. Penguin Books. 